International Journal on Design and Manufacturing Technologies, Vol.2, No.1, July 2008

\title{
THE RECYCLING OF WASTE PET BOTTLES AS A LOW COST ALTERNATIVE COMPOSITE MATERIAL
}

\author{
Mohammad Arif Kamal', Syed Javed A. Rizvi ${ }^{2}$ \\ 'Department of Architecture, Zakir Hussain College of Engineering \& Technology, Aligarh Muslim University, Aligarh, India \\ ${ }^{2}$ Department of Petroleum Studies, Zakir Hussain College of Engineering \& Technology, \\ Aligarh Muslim University, Aligarh, India \\ E-mail: ${ }^{1}$ architectarif@rediffmail.com
}

\begin{abstract}
PET Bottles are finding more and more applications in disposable packaging mainly in beverage segment. As on today not only cola companies are using PET bottles but also fruit juice, mineral water and liquor industries have accepted PET bottles for packaging of their product. The transparent polyethylene terephthalate (PET) bottles have become increasingly common and are used for mineral water, soda waters and soft drinks. These bottles are of - course, very user friendly but environmental hazards are associated with PET Bottles. Huge consumption of these commodities causes volumetrically large PET wastage on daily basis. They contribute a large part in urban garbage. In this paper, an effort has been made to recognize the possible application of waste PET bottles for manufacturing of composite panel for economically feasible architectural and building applications.
\end{abstract}

Key words: Recycling, Composite Panels, Architectural Applications.

\section{INTRODUCTION}

In mid nineties PET Bottles (Polyethylene Terephthalate) were introduced for soft drink packaging first time in our country, since then they have revolutionized the way of packaging for beverage segment. The recent development in PET - PEN blends have made it possible for beer packaging too. Most containers are glossy clear transparent, while some are green in colour. These bottles are use and throw in nature ranging from $500 \mathrm{ml}$ to 2.5 liters in size. Huge consumption of these commodities causes volumetrically large PET wastage on daily basis. Although Polyethylene Terephthalate is a thermoplastic material, but it cannot be straightway reprocessed to make new bottles. The increase in Acetal Aldehyde content while melting PET in recycling extruder causes serious objection for packaging of soft drinks etc. Another problem with PET bottles is their large volume to mass ratio. According to Central Pollution Control Board of India, a 10,000 tonnes capacity exists for manufacturing of PET bottles and assorted containers. Because of durability and glass-like clarity of PET bottles and containers, a major share of these becomes a longterm asset for the users. However, around 50 per cent of current consumption of PET bottles used is available for recycling. Considering the average weight of $27 \mathrm{~g}$ per bottle, 3000 tonnes of PET would amount to 115 million numbers of bottles going into waste that largely remains uncollected and unsold. This figure will multiply many times by 2010 [1].

Although waste PET bottles can be recycled by special recycling plants situated at Madras, Gajraula,
Kanpur and Mumbai, but we emphasized on the use of complete bottle (along with caps) to produce some economically feasible product, without any change in its physical form. These panels can be a very durable solving five issues at the same time:

(1) Reduction in waste PET Bottles (environmental waste).

(2) Thermal insulation of houses and installations.

(3) No importation and transportation of expensive insulation materials.

(4) Reduction in the cost of energy used for heating and cooling of buildings.

(5) No burning of waste causing air pollution.

\section{DESIGN DETAILS OF A COMPOSITE PANEL}

Nowadays Structural Insulated Panels (SIPs) are getting wide acceptance among architects because of their thermal efficiency and faster construction of buildings. They are prefabricated insulated structural elements for use in building walls, ceilings, floors and roofs. SIPs are usually foam core panels, covered with suitable skin materials on both sides as shown in Fig. 1. The most common types of sheathing or skins materials are Oriented Strand Board (OSB) and plywood. Some manufacturers produce panels with fiber-cement sheathing. Composite panels can have facing made up of $3 \mathrm{~mm}$ ply or veneer and the edging made up of aluminum sections or PVC profiles (Fig .2). The shape and size of 
PET bottles composite can be square or rectangular in nature. They can be prefabricated in different sizes such as $300 \mathrm{~mm} \times 300 \mathrm{~mm}, 300 \mathrm{~mm} \times 450 \mathrm{~mm}, 300 \times 600 \mathrm{~mm}$, $450 \mathrm{~mm} \times 450 \mathrm{~mm}, 450 \mathrm{~mm} \times 600 \mathrm{~mm}, 600 \mathrm{~mm} \times 600 \mathrm{~mm}$. The total thickness of the panel comes out to be approximately $100 \mathrm{~mm}$.

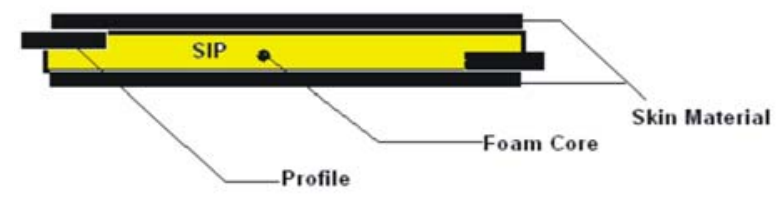

Fig. 1. Conventional Structural Insulated Panel

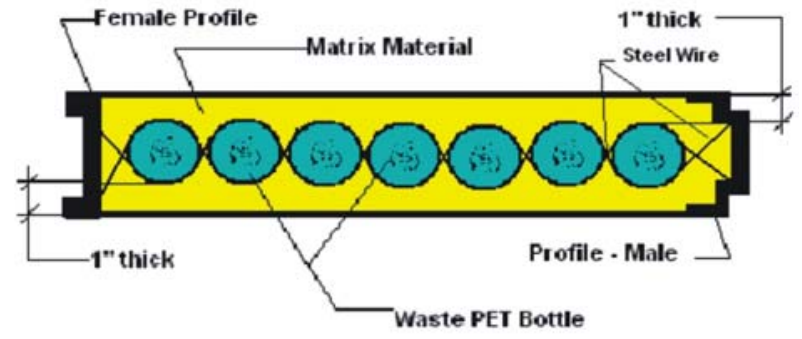

Fig. 2. Structural Insulated Panel using Waste PET Bottles as Voluminous Filler

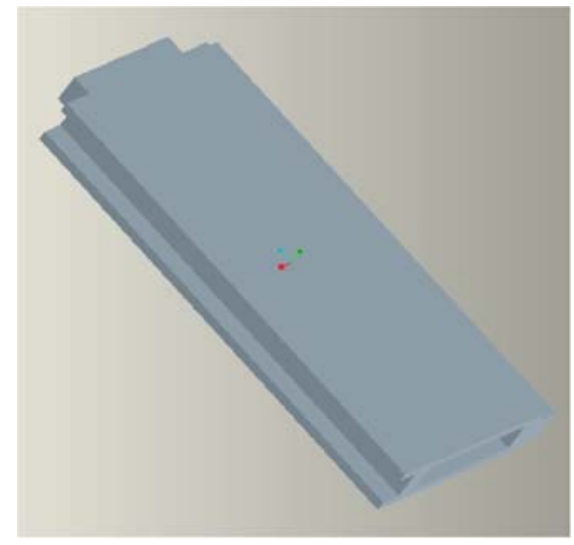

Fig. 3. Three-Dimension model of a Composite Panel

\section{WASTE PET BOTTLE AS LOW COST VOLUMINOUS FILLER MATERIAL FOR INSULATED PANELS}

There are a number of insulation materials, which are being used in manufacturing composite panels. They are:
I. Rigid polyurethane (PUR)
ii. Rigid polyisocyanurate (PIR)
iii. Extruded polystyrene (EPS)
iv. Expanded polystyrene (XPS)
v. Phenolic foam
vi. Mineral fibre

Of these, only rigid polyurethane and polyisocyanurate insulation (collectively called urethanes) expand and autohesively bond to the faces during the manufacturing process. A separate adhesive has to be used to bond the other insulation materials. The autohesive properties make urethane particularly suitable for filling panel profiles and edge details and it is therefore the most commonly used core for composite panels. All the rigid foam insulation materials are produced using chemical blowing agents [2].

But in our case the waste PET Bottles has replaced the costly foam core. PET Bottles can be considered as "Voluminous Filler Material" and hence they will reduce the amount of matrix material. Another main advantage of waste PET Bottles is that these empty bottles contain large volume of air, which acts as insulating material and provides excellent thermal insulation.

\section{Compatibility of PET Bottle with matrix materials}

The compatibility between the matrix material and filler material is governed by the thermodynamics. A negative value of Gibb's free energy $(-\Delta G)$ is essential thermodynamic condition for compatibility. On detailed investigation we can conclude that if the solubility parameters $(\delta)$ are in close range, we can expect the compatibility between matrix material and filler. The solubility parameters for some of the well-known polymers are given below [3]:

\section{Table 1. Solubility Parameters of various polymeric materials}

\begin{tabular}{|llllll|}
\hline S. No. & \multicolumn{2}{c}{$\begin{array}{c}\text { Polymer Matrix } \\
\text { Material }\end{array}$} & $\delta$ & S. No. & \multicolumn{2}{c|}{ Polymer Matrix Material } & $\delta$ \\
1 & PP & 7.9 & 12 & Polysulphide Rubber & $9.0-9.4$ \\
2 & PE & 8.0 & 13 & Polycholoroprene Rubber & $9.2-9.4$ \\
3 & PS & 9.1 & 14 & Polyvinylidene Chloride & $9.8-12.2$ \\
4 & PMMA & 9.2 & 15 & Acetal Resin & 11.1 \\
5 & PC & 9.5 & 16 & ABS & 6.05 \\
6 & PVC & 9.5 & 17 & SAN & 5.2 \\
7 & Nylon -6.6 & 13.6 & 18 & HIPS & 5.2 \\
8 & Polyisoprene (NR) & 8.1 & 19 & PAN & 15.4 \\
9 & SBR & 8.4 & 20 & EVA & 8.6 \\
10 & Polybutadine (PB) & 8.4 & 21 & PVA & 9.5 \\
11 & PTFE & 6.2 & 22 & CA & 10.9 \\
\hline
\end{tabular}

The value of solubility parameter $(\delta)$ for PET is approximately 10.7. It has been found that Waste PET Bottles do not have good compatibility with Plaster of Paris and cement-mortar mixture. But when the matrix of waste PET bottles is tied up with thin wires of steel and encapsulated with either Plaster of Paris or cement mortar mixture there was considerable improvement in panel's strength. Steel wires tied over PET bottles; act as linkage between matrix of PET bottle and matrix material. 
Steel wire mesh also can be used for better strength of panel.

\section{APPLICATIONS OF COMPOSITE PANELS}

PET Bottles composite panels can be pollution free and environment friendly composite material to a large extent. Due to its lightweight, high strength to weight ratio, corrosion resistance, low manufacturing cost and other advantages, PET Bottles based composites can be an important composite material in architectural applications, construction industry and civil engineering works. These panels can be manufactured in various modular sizes and can be used in many applications as per requirement. Some of the possible applications have been summarized as follows:

I. Low-density insulation boards, medium-density boards, hard boards, block board and other building components such as walling units and roofing panels can be manufactured using PET Bottles composites.

ii. An important application can be for roof terracing. These panels can be laid over the Reinforced Cement Concrete (R.C.C) roof slab and panel joints can be finished with epoxy or cement mortar. This will eliminate the traditional cumbersome method of roof terracing i.e. laying of brick tiles over the mud phuska. This will act as thermal insulation on the roof top, which heats up the inerior space and thus it helps in natural cooling and conservation of energy.

iii. They can also be used in cladding of wall exteriors, especially on the south or southwest facade of the building to provide thermal insulation to the building facade from the direct solar radiation.

iv. These panels are expected to be used in place of galvanized iron and asbestoses sheets. Their thermal insulation is better than these conventional sheets. System is ideally suited for providing durable and economical roofing / flooring in the low cost houses especially for economical weaker section of society in rural / urban areas or hilly regions.

v. They can be used as lightweight partitions, false ceiling, colorful laminated panels and lining in interior decoration in buildings.

vi. They can also be used for providing temporary shelters during the rehabilitation work in the case of natural disasters such as Earthquakes, Cyclones and Tsunamis and during the organization of Kumbh/ Maagh Mela etc.

\section{TECHNOLOGICAL GAPS AND FUTURE RESEARCH}

The PET bottles composite panels should not be used as substitutes for conventional structural systems. The concept must exploit the advantages offered by composite panels in terms of lightweight, tailorability, and connectability. In developing innovative design concepts, the way in which performance specifications on structural sub-systems can be utilized needs to be further studied.

The performance and cost of complete PET Bottles composite panels are controlled by their connections and joineries, and little research has been performed to develop connection strategies and details which in the end do not form the weak link in the overall structural system and which are simple, durable and strong. In the research and development of connections, emphasis must be placed on developing light weight, modular, simple, and reliable connectors which can be assembled quickly in order to benefit the construction and assembly process. The economic impact of design concepts in which significant savings can be realized due to systems that reduce assembly costs should be studied. The use of computer simulation to demonstrate new construction methodologies that can show economic advantages should be explored. Industry \& design experts are of the view that with the adoption of advanced technologies and some extent of standardization, these problems could be easily taken care of.

\section{CONCLUSION}

Waste PET bottles composite panel can be an economical alternative material for various architecture, building and civil engineering applications. Still more research and development is required for the prefabrication to the finalization of the complete process for upscaling of technology from lab scale to commercial level.

\section{REFERENCES}

[1] http://www.cpcb.nic.in/sept98v.htm

[2] Brydson, J.A., 1995, Plastic Materials, Fourth Edition, London

[3] Olesky, S.S. and Mohr, J.G., 1964, Handbook of Reinforced Plastics, The Society of Plastics Industries Inc., New York

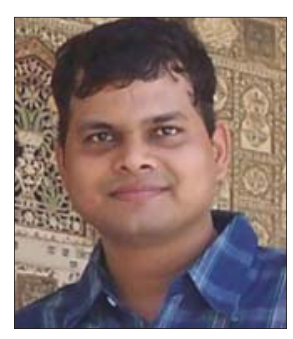

Dr. Mohammad Arif Kamal is an Assistant Professor at the Zakir Hussain College of Engineering \& Technology, Aligarh Muslim University, Aligarh. Awarded the Ministry of Human Resource Development (MHRD) Fellowship to pursue Ph.D. at IIT Roorkee, his areas of interest are Energy Conservation in Buildings, Composite materials, Construction Systems and Materials and Sustainable Architecture. 